\title{
Identifying pan-European management goals for asthma: Participatory action research stud
}

\author{
Axiz Sheikh, Timothy L Frank, Mark L Levy, Ann Dawso
}

\section{Sheikh A}

NHS R\&D Nationa grimary Care Trainin Exello

\section{Frank TL}

Senior Lecturer, Department of Genera Practice, University o Aberdeen

\section{Levy M}

Senior Lecturer Department of Genera Practice, University o Aberdeen

\section{Dawson}

Director, WHO Office fo Quality in Non Communicable Disease snd Condition

\section{Correspondence to:}

Dr Aziz Sheikh Department of Primar Health Care \& Genera Practice,

Imperial College Schoo of Medicine

St Dunstan's Road

Pondon W6 8R

kziz.sheikh@ic.ac.u

Date Submitted: 10/08/0

Date Accepted: 08/09/0

Prim Care Respir

$200110(396-\emptyset$

\section{Introductio}

The disease burden posed by asthma is increasin throughout Europe ${ }^{1}$ Political and informatio technology developments allow greater internationa collaboration between health and related agencies Such sharing and pooling of expertise offer yonsiderable potential to develop an internationall go-ordinated response to the challenge of providin high-quality asthma care in general practice. Ove $90 \%$ of asthma care is provided almost exclusivel within primary care. We aimed to identify pan European management goals for the primary car management of asthma

\section{Methods and result}

iWe used participatory action research methods i order to engage professionals across several Europea countries and to facilitate agreement of a core set $o$ management goals for asthma ${ }^{2}$ Through persona pontacts, we identified primary care asthma grou yepresentatives and key opinion leaders in the primar nare management of asthma throughout Europe. A slectronic database of the e-mail addresses of thi asthma expert group was created.

Eour rounds of an e-mail based adaptation of th Delphi Technique, over a six-month period, were use to arrive at an agreed set of management priorities. I nound one, sixty-two experts were sent by e-mail better stating the aims of the study and asking them $t$ dist important treatment goals of relevance to th primary care management of asthma. The results o these were collated and grouped. One hundred an Eorty-nine goals were identified by this process by th eighteen experts who responded. For round two, th dxperts were asked to score each of the suggeste goals in terms of their importance on a scale from on to nine with nine being the most important. Th bumulative score for each goal was calculated wit scores ranging from 32 to 117 . In order to mak further rounds more focused only those goal dchieving cumulative scores above one hundre progressed to round three. Twenty-one goal grogressed to round three with the experts bein asked to rank each of the goals on a linear scale. Th sleven goals with the highest cumulative score progressed to round four. The expert panel was aske to place these goals in order of importance givin each goal a unique rank on a scale of one to eleven tThe five most important (those achieving the highes score in round four) were considered to be th consensus of the Delphi panel.

Sixty-two experts were identified from seve European countries, of whom a total of $41(66 \%$ contributed to at least one round of the Delph process. From an initial list of 149 suggested goals, i was possible to agree five management objectives fo primary care that are considered to have relevance $t$ primary healthcare providers throughout Europe (Bo d). An international meeting for representatives of th expert group was held in Paris in January 2001, i leonjunction with representatives of the World Healt Organization, the International Primary Car Respiratory Group, the Primary Care and Genera Practice Scientific Group of the European Respirator Group and the General Practice Airways Group a which it was possible to refine these managemen goals and agree a declaration for asthma care $\mathrm{i}$ general practice. Work was also begun toward producing a relevant minimum data set to asses

\section{Box 1: European Primary Care Asthma Goal}

- To increase patient understanding of when and how and to use asthma treatment and how to adjust it according to asthma symptoms (or peak flow reading)

- To increase patient understanding of when to consult for asthma exacerbations

- go decrease the impact of asthma by increasin 'asthma free days' by $30 \%$ within three years

- To decrease severe asthma exacerbations (defined as either requiring a short course of oral steroids or hospitalisation) by $30 \%$ within thre years.

- To decrease preventable asthma deaths by 50 within three years.

progress in achieving these goals

\section{Commen}

The Delphi technique is a method of gaining consensus from a group of experts using a series o dntensive questionnaires interspersed with controlle opinion feedback ${ }^{3}$, The process has three mai features: anonymity, controlled feedback, an btatistical group response. Combining this approac with a meeting of asthma experts it was possible $t$ greate the impetus needed to begin work on creatin she tools and infrastructure needed to assess progres in the realisation of treatment objectives that focus o promoting patient autonomy, increasin gnderstanding, improving quality of life, and reducin serious morbidity and mortality from asthma. W kope that this initiative will in time prove a successful as The St Vincent's Declaration i 


\section{Not to be reproduced without the permission of the Primary Care Respiratory Journa}

mproving the quality of care delivered to people wit diabetes 5

This is, as far as we are aware, the first time that th Delphi technique has been adapted for us electronically; e-mail Delphi rounds offer th advantage of quick, cheap and efficien communication across international boundaries. W believe that there is considerable scope for further us of the methods here developed in other disease area where international collaboration may confe advantage.

Funding General Practice Airways Group funded th Delphi Process; Merck Sharpe and Dohme and Glax Snternational shared the cost of the Paris meeting. A is supported by a NHS R\&D National Primary Car Award.

\section{Conflict of interest None declared}

Contributorship ML and AD conceived the idea fo this project, devising the study methods in conjunctio with TLF and AS. TLF, AS and ML performed dat analysis; the paper was co-written by all four authors ML is the study's guarantor

\section{stcknowledgement}

We wish to thank all those people who contributed $t$ the Delphi process and those who participated in th Paris meeting, whose names follow: Artiguenave MC cotton P, Henrichsen SH, Kleinebreil L, Ostergaard M, Ostrem A, Pallesen R, Roman M, van Schayck O Heloteols B, Tilling B, Thoonen B and van

\section{Reference}

.1. European Community Respiratory Health Survey Ariations in the prevalence of respiratory symptoms self reported asthma attacks and the use of asthm medication in the European Community Respirator Health Survey (ECRHS). Eur Respir J 1996 9:687 95

2. Robson C. Real world research. Oxford Blackwell, 1993;438-44

B. Jones J, Hunter D. Consensus methods for medica and health services research. $\boldsymbol{B M} ; 1995 \mathbf{B 1}: 376-80$

4. Dalkey NC, Helmer O. An experimenta application of the Delphi method to the use of experts Management Sc 1963 9:458-67

5. Diabetes Care and Research in Europe: the $S$ Vincent declaration. Diabet Me 1990 7:360 